\title{
The prevalence of self-reported deliberate self harm in Irish adolescents Carolyn Morey ${ }^{\dagger 1,2}$, Paul Corcoran ${ }^{\dagger 1}$, Ella Arensman*1 and Ivan J Perry ${ }^{\dagger 3}$
}

\begin{abstract}
Address: ${ }^{1}$ National Suicide Research Foundation, 1 Perrott Avenue, College Road, Cork, Ireland, ${ }^{2}$ Inspire Foundation, PO Box 1790 , Rozelle NSW 2039, Australia and ${ }^{3}$ Department of Epidemiology and Public Health, University College Cork, Room 2.51, Brookfield Health Sciences Complex, College Road, Cork, Ireland

Email: Carolyn Morey - carolyn@inspire.org.au; Paul Corcoran - paul.nsrf@iol.ie; Ella Arensman* - ella.nsrf@iol.ie; Ivan J Perry - i.perry@ucc.ie * Corresponding author †Equal contributors
\end{abstract}

Published: 28 February 2008

BMC Public Health 2008, 8:79 doi:10.1 I86/147|-2458-8-79
Received: 18 June 2007

Accepted: 28 February 2008

This article is available from: http://www.biomedcentral.com/I47/-2458/8/79

(C) 2008 Morey et al; licensee BioMed Central Ltd.

This is an Open Access article distributed under the terms of the Creative Commons Attribution License (http://creativecommons.org/licenses/by/2.0), which permits unrestricted use, distribution, and reproduction in any medium, provided the original work is properly cited.

\begin{abstract}
Background: Deliberate self harm is major public health problem, in particular among young people. Although several studies have addressed the prevalence of deliberate self harm among young people in the community, little is known about the extent to which deliberate self harm comes to the attention of medical services, the self harm methods used and the underlying motives. The aim of this study was to determine the prevalence of deliberate self harm in adolescents and the methods, motives and help seeking behaviour associated with this behaviour.
\end{abstract}

Methods: A cross-sectional survey using an anonymous self-report questionnaire was administered in 39 schools in the Southern area of the Health Service Executive, Ireland. Of the 4,583 adolescents aged 15-17 years who were invited to participate in the survey, 3,88I adolescents took part (response: $85 \%$ ).

Results: A lifetime history of DSH was reported by $9.1 \%(n=333)$ of the adolescents. DSH was more common among females (13.9\%) than males (4.3\%). Self cutting $(66.0 \%)$ and overdose $(35.2 \%)$ were the most common DSH methods. A minority of participants accessed medical services after engaging in $\mathrm{DSH}(15.3 \%)$.

Conclusion: DSH is a significant problem in Irish adolescents and the vast majority do not come to the attention of health services. Innovative solutions for prevention and intervention are required to tackle $\mathrm{DSH}$ in adolescents.

\section{Background}

Deliberate self harm (DSH) is a major public health problem in Ireland. Young people are those most at risk, particularly young women aged 15-19 years who had the highest incidence of DSH based on hospital presentations to A\&E departments in 2004, 606 per 100,000[1]. While the rate for young men of the same age is considerably lower, it is also notable at 301 per 100,000[1]. These incidence rates are likely to be the 'tip of the iceberg' as they do not include cases who do not present to hospital after an act of DSH. Deliberate self harm is used to describe different types of behaviours associated with varying levels of suicide intent and a variety of motives.

The self reported lifetime prevalence of DSH found by general population studies of adolescents ranges from $2-8 \%[2-4]$. Two Irish school-based studies have reported a lifetime prevalence of DSH in adolescents. In a sample 
of 88 13-14 year-olds a lifetime prevalence of self harm of $2-3 \%$ was reported [5], while Lynch and colleagues found a lifetime prevalence of deliberate self harm of $1.5 \%$ among adolescents aged 12-15 years [6]. In two studies, the self reported life time prevalence of self harm thougths was reported, which was $44 \%$ [5] and 45.7\%[7].

This paper reports the findings of a large-scale schoolbased survey in Ireland that investigated the prevalence of DSH and self harm thoughts in 15-17 year olds. Details of the methods of DSH, motives for DSH and help seeking behaviour are addressed as well.

\section{Methods \\ Design and sample}

A cross-sectional survey of 3,881 adolescents aged 15-17 years was carried out in 39 schools in the Health Service Executive (HSE) Southern area between January 2003 and March 2004. Power calculations indicated that a minimum of 3,000 students were required to return a $95 \%$ confidence interval of $9.0-11.0 \%$ for a postulated prevalence of $10 \%$ as reported by Hawton and colleagues[8]. A list of all schools within the Southern area of the Health Service Executive was obtained from the Department of Education and schools were then divided according to whether they were in Counties Cork or Kerry or Cork city. They were further categorised as being co-educational, all male or all female. Using a random selection, 54 schools were invited to take part and 39 schools participated in the survey. Of the 4,583 students who were invited to take part, 3,881 participated in the survey, which is a response rate of $85 \%$. Fifty one questionnaires (1.3\%) were excluded from data analysis as they did not fit the age criteria $(n=25)$ or were not filled in seriously $(n=26)$.

The response rate varied by school. For 7 of the 39 schools, the response rate was lower than $75 \%$ whereas 8 schools had a response rate of at least $95 \%$. However, there was no strong association between type of school and response rate. Non-participation was primarily because of absenteeism. In total, $90.7 \%$ of the nonresponding children were absent. Those absent due to illness or deliberately not coming to school would have a health and social profile that would be associated with a higher prevalence of DSH to those in school. However, students were also absent from school because of out-ofschool activities such as day trips and tours etc. This was the primary reason why some schools had a relatively poor response rate. Such students would be likely to have a similar prevalence of DSH to those in school at the time of the survey.

With regard to the participating and non-participating schools, single-sex girls' schools were slightly overrepre- sented among participating schools but no differences were found in terms of city/county location.

\section{Procedure}

Prior to the survey being completed, principals and teaching staff were informed about the procedure. An information sheet and opt out form were also sent to parents. On the day when the survey was carried out, students were also given the opportunity to opt out. The Clinical Research Ethics Committee of the Cork Teaching Hospitals granted ethical approval for this survey.

This survey was part of a European survey known as the Child and Adolescent Self Harm in Europe (CASE) study, which has been administered in 6 countries across Europe and one centre in Australia. A standardised internationally validated, anonymous questionnaire was designed by CASE collaborators and used for data collection by each of the centres.

The questionnaire was administered with a member of the research team being present and completed by students at school in the class room. An introduction explained the anonymity and confidential nature of the data along with the voluntary nature of students' participation. It was clarified to the students that they were free to choose whether to complete any or all of the questionnaire and their choice had no bearing on their school work. Completion of the questionnaire took 20-30 minutes. After participants had completed the survey there was a general discussion about the help and support available for young people in their local communities and each participant received a resource pack, which included a list of services in their local area. Time was made available immediately after the session for individuals who wished to ask further questions. There was also the option of contacting the National Suicide Research Foundation at any time if further assistance was required.

A distinctive characteristic of this study was that participants were asked to describe in their own words, the method(s) they had used to harm themselves. This description was then coded according to a standardised definition of deliberate self harm. The definition of deliberate self harm is as follows: "An act with a non-fatal outcome in which an individual deliberately did one or more of the following:

- Initiated behaviour (for example, self cutting, jumping from a height), which they intended to cause self harm.

- Ingested a substance in excess of the prescribed or generally recognisable therapeutic dose. 
- Ingested a recreational or illicit drug that was an act that the person regarded as self harm.

- Ingested a non-ingestible substance or object."

This definition includes acts that are interrupted before self harm is inflicted, for example, a person removed from a bridge before jumping off or interrupted attempts of hanging, but excludes episodes of self harm by individuals who do not understand the meaning or the outcome of their act, for example due to a learning disability. The following questions were used to identify deliberate self harm: "Have you ever deliberately taken an overdose (e.g. pills or other medication) or tried to harm yourself in some other way (such as cut yourself)?" with response options:No/Yes, once/Yes, more than once. For those who confirmed having engaged in DSH, the questionnaire included further questions about the timing of the last act of DSH (less than $a$ month ago/between a month and a year ago/more than a year ago), and participants were asked to describe details of the self harm act, for example the name of the drug taken in an overdose.

Episodes of deliberate self harm were then classified as a 'yes', 'no' or 'no information given' by three independent raters (CM, $\mathrm{PC}, \mathrm{EA})$ using the standardised criteria (Cohen's Kappa $=0.77)$. In cases where ratings were inconsistent, decisions were made based on majority rating. For those who indicated they had harmed themselves, the questionnaire included a series of questions relating to motives, methods and help seeking behaviour.

Self harm thoughts were examined by the following question: "Have you during the past month or the past year seriously thought about taking an overdose or trying to harm yourself but not actually done so?" with response options: $\mathrm{No} /$ Yes, the last time was in the past month/Yes, the last time was over a month ago, but less than a year ago. For those who reported self harm thoughts, the questionnaire included further questions related to help seeking behaviour.

\section{Data analysis}

Prevalence rates of deliberate self harm and self-harming thoughts were calculated with adjustment for missing data. For the prevalence rates, 95\% binomial confidence intervals were calculated. Relative risks and their associated $95 \%$ confidence intervals were used to assess the differences in prevalence rates between groups.

\section{Results \\ Demographics}

Of the 3,830 questionnaires, $50.2 \%$ were females and the majority $(53.1 \%)$ of students were 16 years of age (Table $1)$. The gender balance of the sample and the proportion attending schools in Cork City and Counties Kerry and Cork were similar to the distribution of the adolescent population in the region. There was a difference in the age distribution as the sample was centred on 16 year-olds. This age accounted for just over half of the sample while the remainder were evenly made up of 15 and 17 yearolds. The general population of 15-17 year-olds were made up of almost equal proportions at each year of age.

\section{Deliberate self harm}

A lifetime history of self reported deliberate self harm was reported by 458 (12.2\%, 95\% CI: $11.2 \%-13.3 \%)$ of the teenagers surveyed (Table 2). Of the total population, 333 (9.1\%, 95\% CI: 8.2\% - 10.1\%) students met the DSH definition. Of those who had harmed themselves, $45.9 \%$ had done so more than once. There were 807 (21.6\%, 95\% CI:

Table I: Description of sample and prevalence of DSH by sociodemographic factors

\begin{tabular}{|c|c|c|c|}
\hline & & Number (\%) & Prevalence of DSH $(95 \% \mathrm{Cl})$ \\
\hline \multirow[t]{2}{*}{ Gender } & Male & 1902 (49.8\%) & $4.4 \%(3.1-5.6 \%)$ \\
\hline & Female & $1915(50.2 \%)$ & $13.9 \%(11.8-16.1 \%)$ \\
\hline \multirow[t]{3}{*}{ Age } & 15 years & $884(23.2 \%)$ & $9.3 \%(7.5-11.2 \%)$ \\
\hline & 16 years & $2021(53.1 \%)$ & $9.4 \%(7.6-11.2 \%)$ \\
\hline & 17 years & $902(23.7 \%)$ & $8.5 \%(6.8-10.3 \%)$ \\
\hline \multirow[t]{3}{*}{ City/County } & Cork City & $996(26.0 \%)$ & $9.4 \%(7.6-11.2 \%)$ \\
\hline & Cork County & 1965 (5I.3\%) & $9.1 \%(7.3-10.9 \%)$ \\
\hline & Kerry County & $869(22.7 \%)$ & $8.9 \%(7.1-10.6 \%)$ \\
\hline \multirow[t]{5}{*}{ Living arrangement } & Both parents & 3224 (84.6\%) & $8.1 \%(6.4-9.8 \%)$ \\
\hline & One parent & $442(11.6 \%)$ & $14.3 \%(12.1-16.4 \%)$ \\
\hline & One parent and a step parent/partner & $100(2.6 \%)$ & $18.1 \%(15.7-20.5 \%)$ \\
\hline & Other family member & $23(0.6 \%)$ & $15.0 \%(12.8-17.2 \%)$ \\
\hline & Other & $22(0.6 \%)$ & $10.5 \%(8.6-12.4 \%)$ \\
\hline
\end{tabular}


Table 2: Prevalence of deliberate self harm

\begin{tabular}{lcccc}
\hline & \multicolumn{2}{c}{ Self report' } & \multicolumn{2}{c}{ Based on standardised DSH description } \\
& N/total respondents & $\%(\mathbf{9 5} \% \mathbf{C l})$ & N/total respondents & $\%(\mathbf{9 5} \% \mathbf{C l})$ \\
Lifetime & $458 / 3747$ & $12.2 \%(11.2 \%-13.3 \%)$ & $333 / 3646$ & $9.1 \%(8.2 \%-10.1 \%)$ \\
- More than a year ago & $173 / 3747$ & $4.6 \%(4.0 \%-5.4 \%)$ & $117 / 3646$ & $3.2 \%(2.7 \%-3.9 \%)$ \\
- Past year & $266 / 3747$ & $7.1 \%(6.3 \%-8.0 \%)$ & $208 / 3646$ & $5.7 \%(5.0 \%-6.5 \%)$ \\
- Past month & $83 / 3747$ & $2.2 \%(1.8 \%-2.7 \%)$ & $65 / 3646$ & $1.8 \%(1.4 \%-2.3 \%)$ \\
\hline
\end{tabular}

Students who had thought of harming themselves but did not go through with it n/total respondents $\%(95 \% \mathrm{Cl})$

\begin{tabular}{lcc}
\hline Past Year & $807 / 3732$ & $21.6 \%(20.3 \%-23.0 \%)$ \\
Past Month & $313 / 3732$ & $8.4 \%(7.5 \%-9.3 \%)$ \\
\hline
\end{tabular}

119 did not specify the time of their last DSH act

28 did not specify the time of their last DSH act

$20.3 \%-23.0 \%$ ) teenagers who reported thinking about harming themselves in the previous year, with girls reporting self harm thoughts twice as likely than boys (29.9\% vs. 13.2\%, Relative Risk (RR) = 2.3, 95\% CI: 1.9- 2.6).

\section{DSH and sociodemographic factors}

Girls were three times more likely to harm themselves than boys (RR = 3.2 $95 \% \mathrm{CI}: 2.5$ - 4.1; Table 1). There was no statistically significant variation with regard to age and similar prevalences of DSH were reported by the students of schools in Cork city and the counties of Cork and Kerry. Living arrangement was associated with significant variation in the prevalence of DSH. Living with both parents was protective. Relative to teenagers with this living arrangement, DSH was significantly more common among those living with one parent $(\mathrm{RR}=1.895 \% \mathrm{CI}: 1.4$ -2.3 ) or one parent and a step parent/partner $(R R=2.2$ $95 \%$ CI: $1.4-3.4)$.

\section{Methods of deliberate self harm}

The majority of the teenagers who engaged in self harm did so by either cutting themselves $(66.0 \%)$ or taking an overdose (35.2\%) (Table 3$)$. Although there was a higher proportion of girls who reported cutting themselves or taking an overdose than boys, this was not significant. It is notable that boys used a greater variety of methods to harm themselves than girls. Of the 333 teenagers who had harmed themselves, $19.8 \%$ did so under the influence of alcohol, while $11.8 \%$ were under the influence of an ille- gal drug at the time when they harmed themselves. Boys $(32.3 \%)$ were twice as likely as girls (15.4\%) to have been under the influence of alcohol when they engaged in DSH $(\mathrm{RR}=2.1,95 \% \mathrm{CI}: 1.3-3.4)$ and four and half times more likely to have taken an illegal drug $(28.1 \% \mathrm{~V} 6.1 \%$, RR = $4.6,95 \% \mathrm{CI}: 2.2-9.5)$. Of the 220 cases of self-cutting, $11.5 \%$ also involved an overdose.

\section{Motives for deliberate self harm}

The two most common motives reported by students for DSH were; "I wanted relief from a terrible situation" (78.9\%) and "I wanted to die" (60.9\%) (Table 4). Boys more often reported wanting to frighten someone as a motive for their DSH than girls ( $40.7 \%$ vs. $23.6 \%$, RR $=1.7,95 \% \mathrm{CI}$ : $1.1-2.6)$. Also, boys were somewhat more likely to report that they wanted to find out if someone really loved them as a motive for there $\mathrm{DSH}(38.2 \%$ vs. $25.8 \%, \mathrm{RR}=1.5$ 95\% CI: 1.0 - 2.2). Of the 333 students who harmed themselves, nobody reported wanting to die as the only motive for DSH.

\section{Help seeking behaviour among those who harmed themselves}

Forty four percent $(43.7 \%, 95 \% \mathrm{CI}: 40.8 \%-47.0 \%)$ of teenagers who harmed themselves sought help prior to them engaging in the DSH, while 49.8\% (95\% CI: $46.9 \%$ - 53.1\%) sought help after the event. Of those seeking help, contacting a friend was the most common source of help sought both before (38.2\%) and after (40.3\%)

Table 3: Methods of deliberate self harm by gender

\begin{tabular}{|c|c|c|c|c|c|c|c|c|}
\hline & Self cutting & Overdose & Alcohol & Recreational Drugs & Self Battery & Hanging & Other & Total \\
\hline Girls & I 74 (68.8\%) & 89 (35.2\%) & $10(4.0 \%)$ & $5(2.0 \%)$ & $7(2.8 \%)$ & $5(2.0 \%)$ & II (4.3\%) & 253 \\
\hline Boys & 45 (57.0\%) & 19 (24.1\%) & $6(7.6)$ & $8(10.1 \%)$ & $5(6.3 \%)$ & $4(5.1 \%)$ & $4(5.1 \%)$ & 79 \\
\hline Total & $220 *(66.0 \%)$ & $108(32.4 \%)$ & $16(4.8 \%)$ & $13(3.9 \%)$ & $12(3.6 \%)$ & $9(2.7 \%)$ & $15(4.5 \%)$ & $333^{*}$ \\
\hline
\end{tabular}

*Gender was unknown in I case of self-cutting

Please note: Percentages add up to more than 100 as multiple methods of DSH are reported 
Table 4: Motives reported for deliberate self harm by gender

\begin{tabular}{|c|c|c|c|c|}
\hline & Females $(N=253) \%$ & Males $(\mathrm{N}=79) \%$ & Relative Risk (M/F) & $95 \% \mathrm{Cl}$ \\
\hline Wanted to get relief from a terrible state of mind & 79.2 & 77.6 & 1.0 & $0.8-1.1$ \\
\hline Wanted to die & 59.7 & 65.0 & I.I & $0.9-1.3$ \\
\hline Wanted to show how desperate I was feeling & 52.1 & 52.8 & 1.0 & $0.7-1.3$ \\
\hline Wanted to punish myself & 43.8 & 49.1 & I.I & $0.8-1.5$ \\
\hline Wanted to find out whether someone really loved me & 25.8 & 38.2 & 1.5 & $1.0-2.2$ \\
\hline Wanted to frighten someone & 23.6 & 40.7 & 1.7 & $1.1-2.6$ \\
\hline Wanted to get some attention & 23.0 & 27.3 & 1.2 & $0.7-1.9$ \\
\hline Wanted to get my own back on someone & 19.7 & 25.0 & 1.3 & $0.7-2.2$ \\
\hline
\end{tabular}

engaging in DSH (Table 5). Teenagers were more likely to contact health services after they had harmed themselves rather than before, likewise family members were more likely to be aware of the self harm after the event. Of those who harmed themselves, only $36(11.3 \%)$ reported that they presented to hospital as a result of their DSH episode.

\section{Discussion}

In this broad representative sample of adolescents aged 15-17 years approximately one in ten reported a previous episode of DSH of whom $45.9 \%$ had done so more than once. The lifetime prevalence of DSH of $9.1 \%$ is higher compared to the prevalence of deliberate self harm reported in previous Irish school-based studies [5-7], which can be explained by the use of a broader definition of self harming behaviour in the present study. Only $11.3 \%$ of teenagers who harmed themselves attended hospital and fewer sought help from other medical services following their episode of DSH, findings which are consistent with other Irish studies $[9,10]$. Given this tendency for adolescents not to seek help and that most studies investigating deliberate self harm are based on hospital treated cases of deliberate self harm [11], previous estimates of the extent of deliberate self harm may have been underestimated.

The one-year prevalence rate based on the study definition criteria was $5.7 \%$. Considering their lifetime history of DSH, $11.3 \%$ of the teenagers had attended hospital at

Table 5: Help seeking behaviour among those who harmed themselves $(n=333)$

\begin{tabular}{lcc}
\hline Source of help & Before DSH & After DSH \\
\hline Family & $7.8 \%$ & $20.5 \%$ \\
Friend & $38.2 \%$ & $40.3 \%$ \\
Teacher & $5.8 \%$ & $6.5 \%$ \\
GP & $1.8 \%$ & $7.7 \%$ \\
Social Worker & $3.3 \%$ & $4.5 \%$ \\
Psychologist/Psychiatrist & $4.0 \%$ & $9.2 \%$ \\
Telephone Helpline & $4.4 \%$ & $1.6 \%$ \\
Drop-in/Advice Centre & $1.1 \%$ & $1.2 \%$ \\
Other & $11.2 \%$ & $7.1 \%$ \\
\hline
\end{tabular}

least once. This figure reduced to $8.3 \%$ when only considering cases of DSH that occurred in the past year. Combining the one-year prevalence and its associated figure for hospital attendance indicated that the annual incidence of hospital-treated adolescent DSH in the region was 473 per 100,000 . This is $54 \%$ higher than the rate of 307 per 100,000 calculated for 15-17 year-olds of the region based on data from the National Registry of Deliberate Self Harm [1]. Possible reasons for this discrepancy include the broader definition used in the school-based study, adolescents underestimating the time to their previous $\mathrm{DSH}$, and DSH episodes going undetected within the hospital system.

Unlike many other self-report studies examining deliberate self harm, in this study a standardised definition of deliberate self harm was used, thereby enabling valid international comparisons with other European countries. The lifetime prevalence of DSH among adolescents in the different regions participating in the CASE study ranged from $4.1 \%$ in The Netherlands [12] to $13.2 \%$ in the United Kingdom [8]. In this context, the lifetime DSH prevalence of $9.1 \%$ among Irish school going adolescents can be considered relatively high. In comparison with prevalence rates reported in international studies using slightly different methodologies and focusing on a broader age range among adolescents, again the prevalence of DSH in Irish adolescents appears to be higher. In a cross-sectional survey among 12 to 15 year olds in the U.S state of Washington, Patton et al. found that 3.7\% reported an episode of DSH in the 12 months prior to the survey, which is lower than the 12 month DSH prevalence $(5.7 \%)$ in the present study [13]. In a general population based survey in Norway among 13-19 year olds, Groholt et al found a life time DSH prevalence of $8.1 \%$, which is fairly similar to the Irish prevalence [4].

One drawback to the use of this definition is that it is likely to have produced a conservative estimate of deliberate self harm amongst Irish adolescents due to the requirement of validating response to the initial DSH question by a detailed description. In the present study, 104 participants responded positive to the initial DSH question, but 
did not provide a detailed description of the self harm act, and were therefore excluded from the analyses.

The current study shows that teenage girls are significantly more likely to harm themselves than teenage boys, which is consistent with a similar study in England. Adolescent girls aged 15 and 16 years were 3.5 times more likely $(11.2 \%$ vs. $3.2 \%)$ to engage in self harm than males of the same age[8]. While this finding has important implications for designing prevention and intervention programs for preventing deliberate self harm and promoting positive mental health, it is important not to neglect adolescent boys as they appear to have the highest risk of taking their life and they are also less likely to talk to someone or seek help if they do have problems $[14,15]$.

Self-cutting was the most common method of deliberate self harm reported by both males and females. This is different compared to the hospital presentations due to DSH by adolescents as monitored by the National Registry of Deliberate Self Harm, where overdose appeared to be the most common method of deliberate self harm[1].

Our findings in relation to the motives for DSH are in line with findings from other studies[16-18]. The most frequently reported motives in our study included, 'wanting to get relief from a terrible situation' (78.9\%) and 'wanting to die' $(60.9 \%)$. It is notable that although 'wanting to die' was the second most frequently reported motive, no participant reported this motive as a single motive for DSH, which reflects an ambivalent attitude whereby the expression of feelings of extreme anxiety that the adolescent wishes to escape from prevail. These findings also support the notion that not all instances of DSH are motivated by suicidality.

\section{Conclusion}

In conclusion, there is an urgent need to address the issue of deliberate self harm amongst Irish adolescents. Programmes and interventions that raise awareness about positive mental health and help seeking behaviours should be considered. Along with health services finding ways to eliminate the barriers felt by adolescents that may prevent them from seeking help and to make contact with adolescents in a youth friendly medium rather than waiting for adolescents to come to health services.

\section{Competing interests}

The author(s) declare that they have no competing interests.

\section{Authors' contributions}

$\mathrm{CM}$ drafted the manuscript and was involved in the data collection and data analysis. PC and IJP were involved in the design of the study. CM and EA were involved in the coordination of the data collection. PC had a leading role in the data analysis. All authors were involved in the interpretation and writing of the final manuscript.

\section{Acknowledgements}

We would like to thank the National Suicide Review Group and the Ireland Funds who provided funding for this study. We would also like to thank Rachel Farrow and Eric Kelleher who helped with data collection, Dr Helen Keeley for her advice and assistance in data collection, Eileen Williamson for her programme support, the school staff who helped us with the study, the students who participated and Dr Nicola Madge and Dr Erik Jan de Wilde for coordinating the study at international level. The research was conducted in collaboration with the Child and Adolescent Self Harm in Europe (CASE) study.

\section{References}

I. National Suicide Research Foundation (NSRF): National Registry of Deliberate Self Harm, Annual Report, 2005 Cork: NSRF; 2007.

2. Kienhorst CW, De Wilde EJ, Van den Bout J, Broese van Groenou MI, Diekstra RFW, Wolters WHG: Self reported suicidal behaviour in Dutch secondary education students. Suicide Life Threat Behav 1990, 20:101-II2.

3. De Wilde EJ: Adolescent suicidal behaviour: a general population perspective. In The International Handbook of Suicide and Attempted Suicide Edited by: Hawton K, van Heeringen K. UK John Wiley and Sons; 2000:263-269.

4. Groholt B, Ekeberg O, Wichstrom L, Haldorsen T: Young suicide attempters: a comparison between a clinical and an epidemiological sample. J Am Acad Child Adolesc Psychiatry 2000, 39(7):868-75.

5. O'Sullivan M, Fitzgerald M: Suicidal Ideation and acts of self harm among Dublin School Children. J Adolesc 1998, 21:427-433.

6. Lynch F, Mills C, Daly I, Fitzpatrick : Challenging times: Prevalence of psychiatric disorders and suicidal behaviours in Irish adolescents. J Adolesc 2006, 29:555-573.

7. Lynch F, Mills C, Daly I, Fitzpatrick C: Challenging times: a study to detect Irish adolescents at risk of psychiatric disorders and suicidal ideation. J Adolesc 2004, 24:44I-45I.

8. Hawton K, Rodham K, Evans E, Weatherall R: Deliberate self harm in adolescents: self report survey in schools in England. $B M]$ 2002, 325:|207-|2|I.

9. Keeley HS, Kelleher MJ: Youth Attitudes to Services in Ireland. Psychiatr Bull 1998, 22:257.

10. Department of Public Health: Suicide In Ireland: A National Study Departments of Public Health on Behalf of the Chief Executive Officers of the Health Boards 200I.

II. Evans E, Hawton K, Rodham K: Factors associated with suicidal phenomena in adolescents: A systematic review of population-based studies. Clin Psychol Rev 2004, 24:957-979.

12. Portzky G, De Wilde EJ, Van Heeringen K: Deliberate self-harm in young people: differences in prevalence and risk factors between The Netherlands and Belgium. Eur Child Adolesc Psychiatry 2007 in press.

13. Patton GC, Hemphill SA, Beyers JM, Bond L, Toumbourou JW, McMorris BJ, Catalano RF: Pubertal stage and deliberate selfharm in adolescents. I Am Acad Child Adolesc Psychiatry 2007, 46:508-I4.

14. Garland AF, Zigler EF: Psychological correlates of help-seeking attitudes among children and adolescents. Am J Orthopsychiatry 1994, 64(4):586-93.

15. Saunders SM, Resnick MD, Hoberman HM, Blum RW: Formal help seeking behaviour of adolescents identifying themselves as having mental health problems. J Am Acad Child Adolesc Psychiatry 1994, 33(5):718-28.

16. Hjelmeland $\mathrm{H}$, Hawton K, Nordvik H: Why People engage in Parasuicide a cross-cultural study of intentions. Suicide Life Threat Behav 2002, 32:380-394.

17. Williams MG: Differences in reasons for taking overdoses in high and low hopelessness groups. Br J Med Psychol 1986, 59:269-277. 
18. Boergers J, Spirito A, Donaldson D: Reasons for adolescent suicide attempts: associations with psychological functioning. J Am Acad Child Adolesc Psychiatry 1998, 37:1 287-1293.

\section{Pre-publication history}

The pre-publication history for this paper can be accessed here:

http://www.biomedcentral.com/1471-2458/8/79/prepub

Publish with Biomed Central and every scientist can read your work free of charge

"BioMed Central will be the most significant development for disseminating the results of biomedical research in our lifetime. " Sir Paul Nurse, Cancer Research UK

Your research papers will be:

- available free of charge to the entire biomedical community

- peer reviewed and published immediately upon acceptance

- cited in PubMed and archived on PubMed Central

- yours - you keep the copyright

Submit your manuscript here:

http://www.biomedcentral.com/info/publishing_adv.asp 